\title{
Editorial
}

\section{Mucormycosis -An indelible black spot of COVID 19}

\author{
Annapurna Ahuja ${ }^{1, *}$ \\ ${ }^{1}$ Dept. of Periodontics and Implant Dentistry, Hazaribag College of Dental Sciences and Hospital, Hazaribagh, Jharkhand, \\ India
}

\section{A R T I C L E I N F O}

Article history:

Received 05-03-2021

Accepted 12-04-2021

Available online 03-06-2021
(C) This is an open access article distributed under the terms of the Creative Commons Attribution License (https://creativecommons.org/licenses/by/4.0/) which permits unrestricted use, distribution, and reproduction in any medium, provided the original author and source are credited.
The second wave of Covid 19 has drowned lives of many people all over the earth and still is unstoppable. Each and every day in the life of millennials is full of fear, worry and stress. Days and nights in this dreadful time are full of unexpected negative news a propos this monster 'CORONA'. Steroid-full body of corona recovered patients have become immunocompromised with their ability to fight against general and oral infections. Consequently, one new complication is on rise, Mucormycosis. It is also known as 'black fungus'. Mucormycosis or Zygomycosis is a rare but deadly fungal infection caused by a fungus mucormycete which is abundant in the environment. This fungus is found everywhere and generally harmless but life threatening in people with low immunity conditions like diabetes, patients on immunosuppressive drugs, steroids, anti-cancer therapy etc. ${ }^{1,2}$

The signs and symptoms of this disease depend upon the site where infection is brewing: ${ }^{1}$

1. Rhinocerebral (sinus and brain) mucormycosis may include: One-sided facial swelling, headache, toothache, jaw pain, nasal or sinus congestion, black lesions on nasal bridge or upper inside of mouth that quickly become more severe and fever

2. Pulmonary (lung mucormycosis may include: Fever, cough, chest pain, Shortness of breath

\footnotetext{
* Corresponding author.

E-mail address: annapurna.ahuja@yahoo.com (A. Ahuja).
}

3. Cutaneous (skin) mucormycosis may include blisters or ulcers, and the infected area which turns black. Other symptoms include pain, warmth, excessive redness, or swelling around a wound.

4. Gastrointestinal mucormycosis may include abdominal pain, nausea and vomiting and gastrointestinal bleeding

5. Disseminated mucormycosis typically occurs in people who are already sick from other medical conditions, so it can be difficult to know which symptoms are related to mucormycosis. Patients with disseminated infection in the brain can develop mental status changes or coma.

\section{Sources and traits: ${ }^{2}$}

The fungus is most commonly found in decaying organic matter, such as leaves, compost piles, and animal dung. These molds thrive all over the environment and are commonly seen in soil, damp wall and old buildings. Infection can occur after someone inhales the spores from the air. People get mucormycosis through contact with fungal spores in the environment. A skin infection can occur after the fungus enters the skin through a burn, or skin injury. Infection of the oral cavity or brain is the most common forms of mucormycosis. One evident feature of this infection is fungal invasion into the blood vessels which results in the formation of blood clots and surrounding tissue 
death due to a loss of blood supply.

\section{Prevention and Management: ${ }^{1}$}

\subsection{Prevention}

Protecting yourself from the environment is the only way to prevent mucomycosis. Avoid areas with a lot of dust like construction or excavation sites or by wearing an N95 respirator mask in these areas. Avoid direct contact with water-damaged buildings and flood water after hurricanes and natural disasters; Avoid activities that involve close contact to soil or dust, such as yard work or gardening. Wear gloves, shoes, long pants and long sleeve shirt while in close contact with soil, damp wall and wooded areas. Regular cleaning with soap and water should be a regular protocol after exposure to soil and dust.

\subsection{Treatment}

The treatment is usually done by Amphotericin B , Posaconazole or Isavuconazole followed by surgical removal of fungal area. Some of the Recent COVID 19 patients in India who got infected with mucomycosis sacrifice their eye to prevent further dissemination to brain.

\section{Conflicts of Interest}

All contributing authors declare no conflicts of interest..

\section{References}

1. Center for disease control and prevention. Mucomycosis [Internet]; [updated 2021; cited 2021 May 23]. . Available from: https://www. cdc.gov/fungal/diseases/mucormycosis/index.html.

2. Wikipedia, the free encyclopedia. Mucomycosis [Internet]; [updated 2021; cited 2021 May 23]. ;Available from: https://en.wikipedia.org/ wiki/Mucormycosis.

\section{Author biography}

Annapurna Ahuja, Professor \& Head

Cite this article: Ahuja A. Mucormycosis -An indelible black spot of COVID 19. J Dent Panacea 2021;3(1):1-2. 